\title{
ADUBAÇÃO NITROGENADA E MOLÍBDICA DA CULTURA DO FEIJ ÃO NA ZONA DA MATA DE MINAS GERAIS(1)
}

\author{
M. I. V. AMANE ${ }^{(2)}$, C. VIEIRA $^{(3)}$, \\ R. F. NOVAIS ${ }^{(4)} \&$ G. A. A. ARAÚJ $O^{(3)}$
}

\begin{abstract}
RESUMO
Três séries de experimentos foram realizadas. Na primei ra, estudaram-se, em dois municí́pios, os efeitos de N, Mo e rizóbio; na segunda, em outro município, os efeitos de quatro doses de $\mathbf{N}\left(0,30,60\right.$ e $\left.90 \mathrm{~kg} \mathrm{ha}^{-1}\right)$ e quatro de $\mathrm{Mo}(0,40,80$ e $120 \mathrm{~g} \mathrm{ha}^{-1}$ ), em um esquema fatorial; e na terceira, em seis municípios, os efeitos das combinações 0-0-0, 0-40-70, 20-0-70 e 20-40-70 de $\mathrm{N}$ no sulco de plantio ( $\mathrm{kg} \mathrm{ha}^{-1}$ ), $\mathrm{N}$ aplicado em cobertura $\left(\mathrm{kg} \mathrm{ha}^{-1}\right)$ e molibdênio $\left(\mathrm{g} \mathrm{ha}^{-1}\right)$, respectivamente. $\mathrm{E} \mathrm{m}$ todos os experimentos, $\mathrm{O}$ Mo nas folhas e o $\mathrm{N}$ em cobertura foram aplicados aproximadamente 25 dias após a emergência das plantas. Todos os experimentos receberam $90 \mathrm{~kg} \mathrm{ha}^{-1}$ de $\mathrm{P}_{2} \mathrm{O}_{5}$, na forma de superfosfato simples, e $60 \mathrm{~kg} \mathrm{ha}^{-1}$ de $\mathrm{K}_{2} \mathrm{O}$, na forma de cloreto de potássio, e os solos eram povoados por estirpes nativas de rizóbio. A inoculação com estirpes selecionadas de rizóbio não teve efeito no rendimento de grãos. A adubação com Mo aumentou a produtividade do feijão, levando a rendimentos máximos com doses que variaram de 70 a $100 \mathrm{~g} \mathrm{ha}^{-1}$, dependendo da adubação nitrogenada: quanto mais $\mathrm{N}$, menor a dose de Mo. A adubação nitrogenada no sulco de plantio também foi essencial, e sua falta nem sempre foi compensada pela aplicação de $\mathbf{N}$ em cobertura. A combinação $\mathbf{N}+\mathrm{Mo}$ trouxe aumentos de produtividade de cerca de 90 a mais de $200 \%$.
\end{abstract}

Termos de indexação: Phaseol us vul garis, nitrogênio, molibdênio, rizóbio.

(1) Recebido para publicação em dezembro de 1997 e aprovado em março de 1999.

(2) Pesquisador do Instituto Nacional de Investigação Agronómica, Maputo, República de Moçambique.

(3) Professor do Departamento de Fitotecnia, Universidade Federal de Viçosa - UFV. CEP 36571-000 Viçosa (MG). Bolsista do CNPq.

(4) Professor do Departamento de Solos, UFV. Bolsista do CNPq. 


\title{
SUMMARY: NITROGEN AND MOLYBDENUM FERTILIZATION OF THE COMMON BEAN CROP IN THE "ZONA DA MATA" REGION, MINAS GERAIS STATE, BRAZIL
}

\begin{abstract}
Three series of experiments were carried out. In the first, the effects of N, Mo, and rhizobium were studied at two municipalities; in the second, conducted at another munici pality, a factorial with four rates of $\mathrm{N}\left(0,30,60\right.$, and $\left.90 \mathrm{~kg} \mathrm{ha}^{-1}\right)$ and four rates of Mo $\left(0,40,80\right.$, and $\left.120 \mathrm{~g} \mathrm{ha}^{-1}\right)$ was studied; and in thethird, at six municipalities, thefollowing combinations of $\mathrm{N}$ at planting time $\left(\mathrm{kg} \mathrm{ha}^{-1}\right), \mathrm{N}$ as sidedressing $\left(\mathrm{kg} \mathrm{ha}^{-1}\right)$ and $\mathrm{Mo}\left(\mathrm{g} \mathrm{ha}^{-1}\right)$ were used, respectivel y: 0-0-0, 0-40-70, 20-0-70, and 20-40-70. In all experiments, Mo (as fol iar spray) and $\mathrm{N}$ (as sidedressing) wereapplied at about 25 days after plant emergence Ordinary superphosphate $\left(90 \mathrm{~kg} \mathrm{ha}^{-1}\right.$ of $\left.\mathrm{P}_{2} \mathrm{O}_{5}\right)$ plus potassium chloride $\left(60 \mathrm{~kg} \mathrm{ha}^{-1}\right.$ of $\left.\mathrm{K}_{2} \mathrm{O}\right)$ were applied as uniform fertilization for all experiments. The soils were contaminated by native strains of Rhizobium. Inoculation with selected strains of Rhizobium had no effect on grain yield. Molybdenum fertilization increased bean yield, and maximum yields were attained with 70 to $100 \mathrm{~g} \mathrm{ha}^{-1}$ of Mo, depending on $\mathrm{N}$ fertilization: smaller rate of Mo was needed when greater dose of $\mathrm{N}$ was used and vice versa. Nitrogen applied at planting time was also essential and its absence could not generally be compensated by side dressing application. The N + Mo combination increased bean yield in approxi mately 90 to $200 \%$.
\end{abstract}

Index terms: Phaseolus vulgaris, nitrogen, molybdenum, Rhizobium.

\section{NTRODUÇÃO}

$\mathrm{Na}$ adubação mineral da cultura do feijão (Phaseolus vulgaris L.), em Minas Gerais, recomenda-sea aplicação de $20 \mathrm{~kg}$ ha-1 de nitrogênio no sulco de plantio, junto ao $\mathrm{P}$ e ao $\mathrm{K}$, mais 30 a 40 kg ha-1 de $\mathrm{N}$ aplicados em cobertura, 20 a 25 dias após a emergência das plantas (CFSEMG, 1989).

Em geral, consideram-se as bactérias dos nódulos radiculares, os rizóbios, pouco eficientes, não fixando quantidade suficiente de $\mathrm{N}$ do ar para satisfazer às necessidades das culturas de feijão, quando se desejam altos rendimentos, daí as altas doses de fertilizantes nitrogenados recomendadas. Diversas causas têm si do apontadas para essa ineficiência dos rizóbios, dentre as quais a pobreza do solo em molibdênio (Siqueira \& Franco, 1988).

O molibdênio é componente de duas enzimas, ambas importantes no metabolismo do nitrogênio: a nitrogenase, essencial à fixação do $\mathrm{N}$ do ar nos nódulos radiculares, e a redutase do nitrato, indispensável ao aproveitamento dos nitratos absorvidos pel ofeijœiro (E pstein, 1975; Vieira, 1994).

Experimentos efetuados nos município de Viçosa, Ponte Nova e Coimbra, na Zona da Mata de Minas Gerais, têm revelado apreciável resposta da cultura do feijão à aplicação do molibdênio (Vieira et al., 1992; Amane et al., 1994; Vieira, 1994; Berger et al., 1996). Esses autores verificaram que, dependendo do solo, a adubação molíbdica chega a "substituir" a adubação nitrogenada, mas, na maioria das vezes,
complementa-Ihe a ação ou torna dispensável a adubação nitrogenada em cobertura.

Berger et al. (1996) verificaram, em Coimbra, que a dose de Mo até então aplicada (20 a $40 \mathrm{~g}$ ha-1) era bem inferior à dose que permitiu obter os mais altos rendimentos de feijão: 80 a $90 \mathrm{~g}$ ha-1. Verificaram, ainda, que a época mais propícia à aplicação desse micronutriente nas fol has do feijoeiro vai do $14^{\circ}$ até o 28 dia após a emergência das plantas.

Os estudos citados não permitiram esclarecer, com maior precisão, qual seria a combinação mais conveniente da adubação $\mathrm{N}+$ Mo na cultura do feijão. Também não se sabe se ocorre resposta à aplicação do Mo em outros municípios da Zona da Mata, além dos três citados. No presente artigo, incluem-se estudos que pretendem contribuir para esclarecer essas dúvidas.

\section{MATERIAL E MÉTODOS}

\section{E feitos de N, Mo e rizóbio}

Dois experimentos foram instalados, um em Leopoldina e outro em Visconde do Rio Branco, municípios da Zona da Mata deMinas Gerais. Foram realizados no outono-inverno, em solo povoado por estirpes nativas de R hizobi um. Amostras de sol o da camada de $0-20 \mathrm{~cm}$ de profundidade, retiradas dos locais dos ensaios, foram submetidas à análise de rotina de fertilidade (Quadro 1). 
Quadro 1. Características químicas e texturais de amostras superficiais $(0-20 \mathrm{~cm})$ dos solos utilizados nos experimentos de $\mathrm{N}$, Mo e rizóbio e de $\mathrm{N}$ x Mo

\begin{tabular}{|c|c|c|c|}
\hline Característica & Leopoldina & $\begin{array}{c}\text { Visconde do Rio } \\
\text { Branco }\end{array}$ & Coimbra \\
\hline pH em água $(1: 2,5)$ & 5,4 & 5,6 & 5,9 \\
\hline $\mathrm{P}$ disponível ${ }^{(1)}\left(\mathrm{mg} \mathrm{dm}^{-3}\right)$ & 5,7 & 6,0 & 6,1 \\
\hline K disponível ${ }^{(1)}\left(\mathrm{mg} \mathrm{dm}^{-3}\right)$ & 26,0 & 27,0 & 80,0 \\
\hline $\mathrm{Ca}^{2+}$ trocável $\left(\mathrm{mmol}_{\mathrm{c}} \mathrm{dm}^{-3}\right)$ & 23,0 & 20,0 & 21,0 \\
\hline $\mathrm{Mg}^{2+}$ trocável $\left(\mathrm{mmol} \mathrm{dm}^{-3}\right)$ & 7,0 & 8,0 & 9,0 \\
\hline $\mathrm{Al}^{3+}$ trocável $\left(\mathrm{mmol}_{\mathrm{c}} \mathrm{dm}^{-3}\right)$ & 0,0 & 0,0 & 0,0 \\
\hline Textura & média & argilosa & média \\
\hline
\end{tabular}

${ }^{(1)}$ Extrator: Mehlich-1.

Os tratamentos foram constituídos pelo arranjo fatorial $2 \times 2 \times 2 \times 2$, em queos fatores foram: rizóbio (sementes inoculadas e não inoculadas), $\mathrm{N}$ no sulco de plantio (0 e $20 \mathrm{~kg}$ ha-1), $\mathrm{N}$ em cobertura (0 e $30 \mathrm{~kg} \mathrm{ha}-1$ ) eMopulverizado nas fol has (0 e20 g ha-1). O N em cobertura e o Mo foram aplicados 22 dias após a emergência das plantas. Preferiu-sea aplicação foliar do micronutriente porque Berger et al. (1995) verificaram que esse método permite melhor resultado quea aplicação por pel etização da semente.

Como fonte de $\mathrm{N}$, empregou-se o sulfato de amônio, e de Mo, o molibdato de amônio. O rizóbio utilizado foi uma mistura, em igual proporção, de três estirpes: BR 322, KIM 5 eBR 10008.

$\mathrm{O}$ delineamento experimental empregado foi o de blocos ao acaso, com quatro repetições. A parcela experimental foi constituída por quatro fileiras de 5,0 m de comprimento, espaçadas de $0,5 \mathrm{~m}$, com, aproximadamente, 15 sementes do feijão 'Ouro Negro' por metro desulco. Na col heita, aproveitaramse os 4,0 m² centrais como área útil.

Todas as parcelas receberam, no sulco de plantio, $90 \mathrm{~kg} \mathrm{ha}-1 \mathrm{deP}_{2} \mathrm{O}_{5}$, na forma de superfosfato simples, e $60 \mathrm{~kg} \mathrm{ha}-1$ de $\mathrm{K}_{2} \mathrm{O}$, na forma decloreto de potássio.

O preparo do sol o constou de uma aração seguida de duas gradagens. Quando necessário, capinas para o controle da flora invasora, tratamentos fitossanitários e irrigações foram feitos.

Apenas em Leopoldina, no período da floração, coletaram-se folhas para determinação do teor de N. Para tanto, for am feitas coletas da terceira fol ha trifoliolada, a partir do topo, em 10 plantas tomadas ao acaso, na área útil de cada parcela. As folhas coletadas foram secas em estufa de ventilação forçada, a $70^{\circ} \mathrm{C}$, até atingirem peso constante; em seguida, foram moídas em moinho tipo Wiley, com peneira de20 mal has por pol egada, ehomogeneizadas. A determinação do $\mathrm{N}$ foi feita por digestão sulfúrica (Lindner, 1944), usando-se uma amostra de 100 mg, seguida de avaliação colorimétrica, utilizando-se o reagente de N essler (J ackson, 1965).

\section{Efeitos de doses de $\mathrm{N}$ e Mo}

O experimento foi realizado em Coimbra (MG), no outono-inverno, em solo povoado por estirpes nativas de Rhizobium. As características químicas e a textura desse sol o encontram-se no quadro 1.

Os tratamentos obedeceram ao arranjo fatorial $4 \times 4$, com três tratamentos adicionais. Os fatores foram: doses de $\mathrm{N}$ em cobertura $\left(0,30,60\right.$ e $\left.90 \mathrm{~kg} \mathrm{ha}^{-1}\right)$ e de $\mathrm{Mo}(0,40,80$ e $120 \mathrm{~g} \mathrm{ha}-1)$. O N foi aplicado na forma de sulfato de amônio e o Mo na de molibdato de amônio. O Mo foi aplicado em uma única vez, em pulverização nas fol has, 22 dias após a emergência (DAE) dos feijoeiros. O adubo nitrogenado foi parcelado da seguinte forma: a dose de $30 \mathrm{~kg} \mathrm{ha}-1$ foi aplicada em uma única vez, $22 \mathrm{DAE}$; a de $60 \mathrm{~kg} \mathrm{ha}^{-1}$ foi parcelada em duas de 30, aplicadas aos 22 e 29 DAE ; ea de $90 \mathrm{~kg} \mathrm{ha}^{-1}$ foi fracionada em três de 30, aplicadas aos 15, 22 e 29 DAE.

Todas as parcelas experimentais receberam, no sulco de plantio, 20 kg ha-1 de N (sulfato deamônio), $90 \mathrm{~kg} \mathrm{ha}^{-1}$ de $\mathrm{P}_{2} \mathrm{O}_{5}$ (superfosfato simples) e $60 \mathrm{~kg} \mathrm{ha}^{-1}$ de $\mathrm{K}_{2} \mathrm{O}$ (cloreto de potássio). Os três tratamentos adicionais não receberam $\mathrm{N}$ no sulco de plantio e compreenderam as seguintes combinações de $\mathrm{N}$ (kg ha-1) e Mo (g ha-1): 0-0,0-80 e 60-80.

Os demais procedimentos experimentais foram iguais aos dos experimentos sobre efeitos de N, Moe rizóbio, à exceção do cultivar, feijão preto 'MeiaNoite'.

\section{Adubação com $\mathbf{N}$ e Mo em seis municípios}

Os experimentos foram instalados nos municípios de Visconde do Rio Branco, Coimbra, Leopoldina, Viçosa, Ponte Nova e Ervália, na Zona da Mata de Minas Gerais. Nos quatro primeiros Iocais, eles foram realizados no outono-inverno; no penúltimo, no inverno-primavera; e, no último, no verão-outono. A análise das características da camada superficial $(0-20 \mathrm{~cm})$ dos sol os encontra-se no quadro 2 . Todos eram povoados por estirpes nativas de rizóbio. 
Quadro 2. Características químicas e texturais de amostras superficiais $(0-20 \mathrm{~cm})$ dos solos utilizados no experimento de $\mathrm{N}$ e Mo, em seis municípios

\begin{tabular}{|c|c|c|c|c|c|c|}
\hline Característica & Visconde do Rio Branco & Coimbra & Leopoldina & Viçosa & Ponte Nova & Ervália \\
\hline pH em água $(1: 2,5)$ & 6,3 & 5,4 & 5,3 & 5,7 & 5,8 & 5,0 \\
\hline P disponível ${ }^{(1)}\left(\mathrm{mg} \mathrm{dm}^{-3}\right)$ & 14,2 & 0,7 & 9,9 & 40,0 & 7,7 & 5,1 \\
\hline $\mathrm{K}$ disponível ${ }^{(1)}\left(\mathrm{mg} \mathrm{dm}^{-3}\right)$ & 112,0 & 9,0 & 20,0 & 98,0 & 78,0 & 35,0 \\
\hline $\mathrm{Ca}^{2+}$ trocável $\left(\mathrm{mmol}_{\mathrm{c}} \mathrm{dm}^{-3}\right)$ & 46,0 & 11,0 & 18,0 & 34,0 & 35,0 & 26,0 \\
\hline $\mathrm{Mg}^{2+}$ trocável $\left(\mathrm{mmol}^{\left.-\mathrm{dm}^{-3}\right)}\right.$ & 8,0 & 4,0 & 6,0 & 4,0 & 7,0 & 5,0 \\
\hline $\mathrm{Al}^{3+}$ trocável $\left(\mathrm{mmol}_{\mathrm{c}} \mathrm{dm}^{-3}\right)$ & 0,0 & 0,0 & 0,0 & 0,0 & 0,0 & 5,0 \\
\hline Textura & argilosa & média & média & média & média & média \\
\hline
\end{tabular}

${ }^{(1)}$ Extrator: Mehlich-1.

Utilizou-se o delineamento experimental em blocos ao acaso, com cinco repetições e os seguintes tratamentos, indicados pelas doses de $\mathrm{N}$ (em kg ha-1) aplicadas no sulco de plantio (NP) e em cobertura (NC), e pela dose de Mo (em g ha-1): ONP-ONC-OMo, ONP-40N C-70Mo, 20NP-ONC-70Mo e 20NP-40NC$70 \mathrm{M}$ o. Aumentou-sea dose de Mo, tendo em vista os resultados obtidos por Berger et al. (1996) e os resultados alcançados nos ensaios anteriormente descritos. O sulfato de amônio foi a fonte de $\mathrm{N}$ e o molibdato de sódio, a da Mo. O N em cobertura e o Mo nas folhas foram aplicados 25 dias após a emergência.

O preparo do solo, em Visconde do Rio Branco, Coimbra, Leopoldina e Viçosa, constou de uma aração e duas gradagens, mas em Ponte Nova e Ervália, em áreas de pequenos agricultores, foi utilizado apenas arado de tração animal, e os sulcos de plantio foram abertos manual mente, com enxada.

\section{RESULTADOS E DISCUSSÃO}

\section{Efeitos de N, Mo e rizóbio}

Tanto em Visconde do Rio Branco como em Leopol dina, houve efeito significativo do $\mathrm{N}$ aplicado no sulco de plantio (NP), do N em cobertura (NC) e do Mo sobre a produtividade de grãos. A inoculação com rizóbio não teve efeito e nenhuma interação foi significativa (Quadro 3).

A presença do inoculante não favoreceu a produtividade porque as estirpes não foram eficientes na fixação de $\mathrm{N}$ ou porque seu efeito pode ter sido anulado pelas estirpes nativas do solo, presentes em todos os tratamentos. Como se notou boa nodulação nas raízes dos feijoeiros, acredita-se que a segunda hi pótese seja a mais provável. Vieira (1994) já havia observado que, quando bem manejadas (boa adubação, irrigação, aplicação de Mo), as estirpes nativas podem ser bem eficientes.
Em Visconde do Rio Branco, o NP trouxe um incremento de produção de $38 \%$ em relação aos tratamentos sem NP, NC e Mo, enquanto, com o NC, esse aumento foi de $41 \%$ (Quadro 3). O efeito isolado do Mo foi mais pronunciado, pois promoveu um aumento de $105 \%$. Em Leopoldina, esses incrementos foram de, respectivamente, 92, 72 e 131\% (Quadro 3).

A maior produtividade em Visconde do Rio Branco, $2.868 \mathrm{~kg} \mathrm{ha}^{-1}$, foi alcançada com a combinação de NP, NC e Mo, ao passo que, em Leopol dina, o maior rendimento, $2.585 \mathrm{~kg} \mathrm{ha}-1$, foi atingi do com a combinação de NP e M o. Em relação à testemunha (tratamento sem-0-0-0), essas produções máximas resultaram em aumentos de 229 e $362 \%$, respectivamente.

A adubação nitrogenada em cobertura tem sido indicada quando o feijoeiro exibe pequeno crescimento e fol hagem verde-amarelada, sintomas típicos de carência de N (Vieira, 1978). O presente estudo demonstrou que, quando seaplica NP e, mais tarde, Monas fol has, oNC podeser dispensado, como ocorreu em Leopol dina, onde os tratamentos 20NPONC-20Mo e 20NP-30NC-20Mo produziram praticamente o mesmo (cerca de $2.500 \mathrm{~kg} \mathrm{ha}-1$ ). Entretanto, em Visconde do Rio Branco, apesar de as plantas não exi birem sintomas de carência de N, o NC trouxe aumento adicional médio de cerca de $400 \mathrm{~kg}$ ha-1 nos tratamentos 20NP-30NC-20M o, quando comparados com os tratamentos 20NP-ONC20Mo. Não se conseguiu explicar o porquê dessa diferença dos dois experimentos. Dequalquer forma, os resultados apresentados comprovam que, quando não se emprega NP, o NC pode substituí-lo, pelo menos parcialmente.

O molibdênio sozinho trouxe incrementos de produtividade consideráveis, mas a associação $\mathrm{N}+$ Mo foi a quepossibilitou os maiores rendimentos. Em Visconde do Rio Branco, os tratamentos $\mathrm{N}+\mathrm{Mo}$ produziram, em média, $2.448 \mathrm{~kg}$ ha-1, enquanto, nos tratamentos NP + NC sem Mo, a produtividade foi 
Quadro 3. Resposta da cultura do feijão à inoculação com rizóbio e à adubação nitrogenada e molíbdica, nos experimentos de Visconde do Rio Branco e de Leopoldina

\begin{tabular}{|c|c|c|c|c|c|c|}
\hline \multirow{2}{*}{ I noculação } & \multirow{2}{*}{$\begin{array}{l}\text { Nitrogênio } \\
\text { no plantio }\end{array}$} & \multirow{2}{*}{$\begin{array}{c}\text { Nitrogênio } \\
\text { em cobertura }\end{array}$} & \multirow{2}{*}{ Mo } & \multirow{2}{*}{$\begin{array}{l}\text { V. Rio Branco } \\
\text { Produção(1) }\end{array}$} & \multicolumn{2}{|c|}{ Leopoldina } \\
\hline & & & & & Produção(1) & Teor de $\mathrm{N}$ nas folhas(2) \\
\hline & \multicolumn{2}{|c|}{$\mathrm{kg} \mathrm{ha}^{-1}$} & $\mathrm{~g} \mathrm{ha}^{-1}$ & \multicolumn{2}{|c|}{$\mathrm{kg} \mathrm{ha}^{-1}$} & $\mathrm{~g} \mathrm{~kg}^{-1}$ \\
\hline Sem & 0 & 0 & 0 & 871 & 560 & 28,2 \\
\hline Sem & 0 & 0 & 20 & 1.628 & 1.330 & 32,0 \\
\hline Sem & 0 & 30 & 0 & 1.174 & 980 & 35,1 \\
\hline Sem & 0 & 30 & 20 & 2.569 & 1.675 & 35,8 \\
\hline Sem & 20 & 0 & 0 & 1.098 & 1.100 & 32,4 \\
\hline Sem & 20 & 0 & 20 & 2.695 & 2.550 & 35,6 \\
\hline Sem & 20 & 30 & 0 & 1.807 & 2.350 & 40,6 \\
\hline Sem & 20 & 30 & 20 & 2.409 & 2.490 & 39,5 \\
\hline Com & 0 & 0 & 0 & 875 & 585 & 29,0 \\
\hline Com & 0 & 0 & 20 & 1.956 & 1.315 & 32,9 \\
\hline Com & 0 & 30 & 0 & 1.282 & 985 & 36,5 \\
\hline Com & 0 & 30 & 20 & 2.359 & 1.690 & 37,7 \\
\hline Com & 20 & 0 & 0 & 1.313 & 1.095 & 36,1 \\
\hline Com & 20 & 0 & 20 & 1.786 & 2.585 & 34,3 \\
\hline Com & 20 & 30 & 0 & 1.836 & 2.420 & 41,6 \\
\hline Com & 20 & 30 & 20 & 2.868 & 2.583 & 41,5 \\
\hline Sem (média) & & & & 1.781 & 1.629 & 34,9 \\
\hline Com (média) & & & & 1.784 & 1.652 & 36,2 \\
\hline & 0 (média) & & & 1.589 & 1.140 & 33,4 \\
\hline & 20 (média) & & & 1.976 & 2.141 & 37,7 \\
\hline & & 0 (média) & & 1.528 & 1.390 & 32,6 \\
\hline & & 30 (média) & & 2.038 & 1.891 & 38,5 \\
\hline & & & 0 (média) & 1.282 & 1.259 & 34,9 \\
\hline & & & 20 (média) & 2.284 & 2.022 & 36,2 \\
\hline C.V. (\%) & & & & 24,1 & 7,5 & 8,8 \\
\hline
\end{tabular}

(1) Houve efeito significativo $(P<0,01)$ do $N$ no plantio, $N$ em cobertura e do $M$ o; nenhuma interação foi significativa $(P>0,05)$.

(2) Houve efeito significativo $(P<0,01)$ do $N$ no plantio e do $N$ em cobertura.

de $1.822 \mathrm{~kg} \mathrm{ha}-1$, uma diferença de $34 \%$. Em Leopoldina, esses rendimentos foram de, respectivamente, 2.262 e $2.385 \mathrm{~kg}$ ha-1. O efeito favorável de $\mathrm{N}+$ Mo sobre o rendimento da cultura do feijão já havia sido demonstrado (Vieira et al., 1992; Amane et al., 1994).

Em Leopoldina, o teor foliar de $\mathrm{N}$ aumentou significativamente apenas com NP ou NC (Quadro 3). Sem esses fatores, o teor médio foi de $28,6 \mathrm{~g} \mathrm{~kg}^{-1}$ enquanto com NP + NC foi de $41,1 \mathrm{~g} \mathrm{~kg}^{-1}$, um acréscimo de 44\%. Berger et al. (1996) encontraram efeito significativo do Mo sobre o teor de $\mathrm{N}$ nas folhas, com aumentos de 21 e 44\%, em Viçosa e Coimbra, respectivamente.

\section{Efeitos de doses de $\mathrm{N}$ e Mo}

O efeito do NC sobre a produtividade de grãos (Quadro 4) foi linear, ao passo que o do Mo foi quadrático ( $\hat{\mathrm{Y}}=1.123+15,726 * * \mathrm{Mo}-0,077 * * \mathrm{Mo}+$ $\left.7,557^{* *} \mathrm{~N}-0,051^{* *} \mathrm{NM} 0 ; \mathrm{R}^{2}=0,84\right)$. A quantidade de micronutriente necessária para a obtenção do rendimento máximo variou de acordo com a dose de N. Quando o NC não foi empregado, a produtividade máxima foi obtida com $102 \mathrm{~g} \mathrm{ha-1}$ de Mo; com $30 \mathrm{~kg} \mathrm{ha}-1$ de NC, a dose de Mo necessária para o rendimento máximo foi de $92 \mathrm{~g}$ ha-1; com $60 \mathrm{~kg} \mathrm{ha}-1$ de NC, de $82 \mathrm{~g} \mathrm{ha}-1$ de Mo; e quando se usou a dose de $90 \mathrm{~kg} \mathrm{ha}-1$ de NC, a dose de Mo baixou para $72 \mathrm{~g}$ ha-1. Esses resultados concordam com os de Berger et al. (1996), que obtiveram, em Viçosa e Coimbra, a produção máxima com $80-90 \mathrm{~g}$ ha-1 de Mo e 600 kg ha-1 da fórmula 4-14-8 no sulco de plantio. Em Lavras, sul de Minas Gerais, Rodrigues et al. (1996) conseguiram a produção máxima de feijão com 76 a $81 \mathrm{~g}$ ha-1 de Mo, mas não mencionam se utilizaram $\mathrm{N}$ na adubação. A produtividade máxima estimada ( $\left.2.206 \mathrm{~kg} \mathrm{ha}^{-1}\right)$ seria obtida com 
Quadro 4. Resposta da cultura do feijão a doses crescentes de N e Mo, em Coimbra

\begin{tabular}{|c|c|c|c|}
\hline $\mathbf{N}$ & Mo & Produção & Teor de $\mathbf{N}$ nas folhas \\
\hline $\mathrm{kg} \mathrm{ha}^{-1}$ & $\mathrm{~g} \mathrm{ha}^{-1}$ & $\mathrm{~kg} \mathrm{ha}^{-1}$ & $\mathrm{~g} \mathrm{~kg}^{-1}$ \\
\hline $\begin{array}{l}0 \\
0 \\
0 \\
0\end{array}$ & $\begin{array}{r}0 \\
40 \\
80 \\
120\end{array}$ & $\begin{array}{c}868 \\
1.678^{1,2} \\
1.838^{1,2} \\
1.905^{1,2}\end{array}$ & $\begin{array}{l}25,7^{2,3} \\
41,1^{1} \\
45,1^{1,2} \\
44,9^{1,2}\end{array}$ \\
\hline $\begin{array}{l}30 \\
30 \\
30 \\
30\end{array}$ & $\begin{array}{r}0 \\
40 \\
80 \\
120\end{array}$ & $\begin{array}{l}1.475^{1,2} \\
1.955^{1,2} \\
2.138^{1,2,3} \\
1.863^{1,2}\end{array}$ & $\begin{array}{l}29,8^{3} \\
42,8^{1} \\
42,6^{1} \\
42,0^{1}\end{array}$ \\
\hline $\begin{array}{l}60 \\
60 \\
60 \\
60\end{array}$ & $\begin{array}{r}0 \\
40 \\
80 \\
120\end{array}$ & $\begin{array}{l}1.760^{1,2} \\
1.995^{1,2} \\
1.978^{1,2} \\
2.003^{1,2}\end{array}$ & $\begin{array}{l}38,4^{1} \\
39,6^{1} \\
42,5^{1} \\
41,8^{1}\end{array}$ \\
\hline $\begin{array}{l}90 \\
90 \\
90 \\
90\end{array}$ & $\begin{array}{r}0 \\
40 \\
80 \\
120\end{array}$ & $\begin{array}{l}1.725^{1,2} \\
1.960^{1,2} \\
2.160^{1,2,3} \\
2.140^{1,2,3}\end{array}$ & $\begin{array}{l}37,61 \\
40,91 \\
40,61 \\
41,11\end{array}$ \\
\hline $\begin{array}{r}0^{*} \\
0 * \\
60 *\end{array}$ & $\begin{array}{r}0 \\
80 \\
80\end{array}$ & $\begin{array}{l}440 \mathrm{c}^{* * * *} \\
915 \mathrm{~b} \\
1.643 \mathrm{a}\end{array}$ & $\begin{array}{l}23,4 \mathrm{~b}^{* * *} \\
37,6 \mathrm{a} \\
39,1 \mathrm{a}\end{array}$ \\
\hline $\begin{array}{l}0 \text { (média**) } \\
30 \text { (média) } \\
60 \text { (média**) } \\
90 \text { (média) }\end{array}$ & & $\begin{array}{l}1.572 \\
1.858 \\
1.934 \\
1.996\end{array}$ & $\begin{array}{l}39,2 \\
39,3 \\
40,6 \\
40,1\end{array}$ \\
\hline & $\begin{array}{l}0 \text { (média**) } \\
40 \text { (média) } \\
80 \text { (média**) } \\
120 \text { (média) }\end{array}$ & $\begin{array}{l}1.457 \\
1.897 \\
2.028 \\
1.978\end{array}$ & $\begin{array}{l}32,9 \\
41,1 \\
42,7 \\
42,5\end{array}$ \\
\hline C.V. (\%) & & 14,9 & 8,4 \\
\hline
\end{tabular}

*Tratamentos adicionais que não receberam $20 \mathrm{~kg} \mathrm{ha}^{-1}$ de $\mathrm{N}$ no sulco de plantio. **Não incluindo os tratamentos adicionais. *** Letra diferente indica diferença significativa pelo teste de Tukey a $5 \%$.

1,2,3 Médias seguidas por estes números diferem, significativamente, pelo teste de Dunnett (5\%), dos adicionais 0-0, 0-80 e 60-80, respectivamente.

$90 \mathrm{~kg} \mathrm{ha}-1$ de NC $+72 \mathrm{~g} \mathrm{ha-1}$ de Mo (além dos $20 \mathrm{~kg} \mathrm{ha}^{-1}$ de NP).

Os tratamentos adicionais revelaram que a aplicação de somente $20 \mathrm{~kg} \mathrm{ha}^{-1}$ de $\mathrm{N}$ no sulco de plantio aumentou a produtividade em $97 \%$ (Quadro 4). Sem esse N, a aplicação de $80 \mathrm{~g} \mathrm{ha}^{-1} \mathrm{de}$ Mo aumentou o rendimento em $108 \%$. J untas, as duas aplicações trouxeram um aumento de $318 \%$ no rendimento de feijão, evidenciando a importância do uso de $\mathrm{N}$ no sulco de plantio.

$\mathrm{O}$ efeito do NC sobre o teor de $\mathrm{N}$ nas fol has foi linear, enquanto o do Mo foi quadrático $\hat{Y}=2,86+$ $0,0301 * *$ Mo - 0,00013**Mo2 + 0,0101**N $\left.0,00051 * N M o ; R^{2}=0,85\right)$. Quando o NC não foi empregado, o teor máximo de $\mathrm{N}$ nas fol has foi obtido com 119 g ha-1 de Mo; com 30 kg ha-1 de NC, a dose de Mo necessária para atingir esse máximo foi de $100 \mathrm{~g} \mathrm{ha}^{-1}$; com $60 \mathrm{~kg} \mathrm{ha}^{-1}$ de NC, foi de $81 \mathrm{~g} \mathrm{ha}^{-1}$ de Mo; e com $90 \mathrm{~kg} \mathrm{ha-1}$ de NC, foi de $65 \mathrm{~g} \mathrm{ha}^{-1}$ de Mo.
Quanto a esseaspecto, houve certa concordância com os dados referentes à produção. Portanto, apenas $20 \mathrm{~kg} \mathrm{ha}^{-1}$ de NP combinados com $119 \mathrm{~g} \mathrm{ha}^{-1}$ de Mo permitiram o teor máximo de $\mathrm{N}$ nas folhas.

Os tratamentos adicionais mostraram que, sem $\mathrm{NP}, \mathrm{NC}$ e Mo, o teor de $\mathrm{N}$ nas fol has atingiu apenas 23,4 $\mathrm{g} \mathrm{kg}^{-1}$ (Quadro 4). Com a aplicação isolada de $80 \mathrm{~g} \mathrm{ha}^{-1}$ de Mo, o teor de $\mathrm{N}$ passou para $37,6 \mathrm{~g} \mathrm{~kg}^{-1}$, ou seja, houve um incremento de $61 \%$; esta dose do micronutrientemais $60 \mathrm{~kg} \mathrm{ha}^{-1}$ de NC proporcionaram um incremento um pouco maior: $67 \%$. De novo, constata-se importância do NP, pois, com ele, oMo teve efeito apreciável no teor de $\mathrm{N}$ nas fol has.

\section{Adubação com N e Mo em seis municípios}

Em todos os municípios, os rendimentos obtidos com os tratamentos 20NP-0NC-70Mo e20NP-40NC70M o não diferiram significativamente (Quadro 5). Em três municípios (Visconde do RioBranco, Viçosa 
Quadro 5. Resposta da cultura do feijão a doses crescentes de N e Mo em seis municípios da Zona da Mata de Minas Gerais ${ }^{(1)}$

\begin{tabular}{|c|c|c|c|c|c|c|}
\hline Adubação NP-NC-Mo & Visconde do Rio Branco & Coimbra & Leopoldina & Viçosa & Ponte Nova & Ervália \\
\hline & \multicolumn{6}{|c|}{ - Produtividade em kg ha-1 } \\
\hline $\begin{array}{l}0-0-0 \\
0-40-70 \\
20-0-70 \\
20-40-70\end{array}$ & $\begin{array}{l}1.064 \mathrm{~b} \\
1.894 \mathrm{ab} \\
2.068 \mathrm{a} \\
2.114 \mathrm{a}\end{array}$ & $\begin{array}{r}602 \mathrm{c} \\
1.964 \mathrm{~b} \\
2.190 \mathrm{a} \\
2.318 \mathrm{a}\end{array}$ & $\begin{array}{r}742 \mathrm{c} \\
1.796 \mathrm{~b} \\
2.244 \mathrm{a} \\
2.286 \mathrm{a}\end{array}$ & $\begin{array}{r}776 \mathrm{~b} \\
1.794 \mathrm{a} \\
2.058 \mathrm{a} \\
2.136 \mathrm{a}\end{array}$ & $\begin{array}{r}428 \mathrm{~b} \\
832 \mathrm{a} \\
950 \mathrm{a} \\
1.112 \mathrm{a}\end{array}$ & $\begin{array}{l}\quad 415 \mathrm{c} \\
1.021 \mathrm{~b} \\
1.123 \mathrm{ab} \\
1.344 \mathrm{a}\end{array}$ \\
\hline \multirow[t]{2}{*}{ C.V. (\%) } & 29,0 & 6,3 & 8,7 & 14,4 & 19,1 & 13,5 \\
\hline & \multicolumn{6}{|c|}{ - Teor de $\mathrm{N}$ nas folhas em $\mathrm{g} \mathrm{kg}^{-1}$} \\
\hline $\begin{array}{l}0-0-0 \\
0-40-70 \\
20-0-70 \\
20-40-70\end{array}$ & $\begin{array}{l}20,6 \mathrm{~b} \\
30,9 \mathrm{a} \\
26,4 \mathrm{a} \\
31,8 \mathrm{a}\end{array}$ & $\begin{array}{l}17,8 \mathrm{~b} \\
23,5 \mathrm{ab} \\
20,8 \mathrm{~b} \\
24,4 \mathrm{a}\end{array}$ & $\begin{array}{l}19,2 \mathrm{c} \\
27,0 \mathrm{ab} \\
24,6 \mathrm{~b} \\
30,5 \mathrm{a}\end{array}$ & $\begin{array}{l}26,0 \mathrm{~b} \\
32,6 \mathrm{a} \\
32,8 \mathrm{a} \\
34,6 \mathrm{a}\end{array}$ & $\begin{array}{l}18,6 \mathrm{c} \\
22,0 \mathrm{~b} \\
22,4 \mathrm{~b} \\
25,4 \mathrm{a}\end{array}$ & $\begin{array}{l}19,7 \mathrm{~b} \\
28,4 \mathrm{a} \\
27,5 \mathrm{a} \\
31,5 \mathrm{a}\end{array}$ \\
\hline C.V. (\%) & 11,1 & 9,0 & 10,2 & 6,7 & 6,0 & 10,5 \\
\hline
\end{tabular}

(1) Em cada local, médias seguidas por, pelo menos, uma mesma letra, não diferem significativamente pelo teste de Tukey a 5\%. $\mathrm{NP}=\mathrm{N}$ no sulco de plantio $\left(\mathrm{kg} \mathrm{ha}^{-1}\right), \mathrm{NC}=\mathrm{N}$ em cobertura $\left(\mathrm{kg} \mathrm{ha}^{-1}\right), \mathrm{Mo}=$ molibdênio nas folhas $\left(\mathrm{g} \mathrm{ha}^{-1}\right)$.

e Ponte Nova), o tratamento 20NP-40NC-70Mo também não diferiu significativamente do ONP40NC-70Mo. Os tratamentos com NP e Mo deram produções que foram 94 a $285 \%$ mais altas que as do ONP-ONC-OMo.

Nos tratamentos 20NP-40NC-70Moe20NP-0NC70 Mo, as plantas exibiram, desde o início, crescimento vigoroso e fol has verde-escuras, sobretudo no primeiro tratamento. No ONP-40NC70Mo, os feijoeiros apresentaram-se, inicialmente, com pouco crescimento e fol has verde-amareladas, recuperando-se com o NC e o Mo, embora sem atingir o crescimento das plantas dos tratamentos 20NP. 40N C-70M oe 20N P-0N C-70M o. No ONP-ONC-0Mo, os feijoeiros revelaram fraco crescimento e fol has verde-amareladas ou mesmo amareladas. Verificase, portanto, que, aplicando-se NP + Mo, não houve necessidade de NC, e que, em geral, o NC não substituiu a contento o NP.

Quanto ao teor de N nas fol has (Quadro 5), os tratamentos com NC proporcionaram as maiores médias, sem diferenças significativas, com uma exceção (Ponte Nova). Em três municípios, o tratamento 20NP-0NC-70Mo não diferiu, significativamente, do 20N P-40N C-70M o. O tratamento ONP-ONC-OM o proporcionou sempreas menores médias. Comparando com os dados de produtividade, verifica-se que os maiores teores de $\mathrm{N}$ nas fol has nos tratamentos ONP-40NC-70M o nem sempre se traduziram em maiores produções; nesse aspecto, 20NP-ON C-70M o sobressaiu, embora com teores foliares de $\mathrm{N}$ significativamente menores em alguns casos.

\section{CONCLUSÕES}

1. A inoculação com estirpes selecionadas de rizóbio não aumentou o rendimento do feijão.

2. A adubação com Mo foi essencial à cultura do feijão. Para as máximas produções, as doses de Mo variaram de 70 a $100 \mathrm{~g}$ ha-1, sendo necessárias as mai ores doses com as menores doses de $\mathrm{N}$.

3. A adubação nitrogenada no sulco de plantio foi essencial e sua falta nem sempre foi compensada pela adubação nitrogenada em cobertura.

4. Na presença da adubação fosfatada epotássica, a combinação N + Mo trouxe aumentos de produção de feijão que variaram de 90 a mais de $200 \%$.

\section{LITE RATURA CITADA}

AMANE, M.I.V.; VIEIRA, C.; CARDOSO, A.A. \& ARAÚJ O, G.A.A. Resposta de cultivares de feijão (Phaseol us vulgaris $L$.) às adubações nitrogenada e molíbdica. R. Ceres, 41:202-216, 1994.

BERGER, P.G.; VIEIRA, C. \& ARAÚJ O, G.A.A. Efeitos de doses eépocas de aplicação do molibdênio sobrea cultura do feijão. Pesq. Agropec. Bras., 31:473-480, 1996.

BERGER, P.G.;VIEIRA, C.; ARAÚJ O, G.A.A. \& CASSINI, S.T.A. Peletização de sementes de feijão (Phaseolus vulgaris L.) com carbonato de cálcio, rizóbio e molibdênio. R. Ceres, 42:562-574, 1995.

COMISSÃO DE FERTILIDADE DO SOLO DO ESTADO DE MINAS GERAIS - CFSEMG. Recomendações para o uso de corretivos efertilizantes em Minas Gerais. Lavras, 1989. $159 p$. 
EPSTEIN, E. Nutrição mineral das plantas. Princípios e perspectivas. Rio de J aneiro, Livros Técnicos e Científicos, 1975. 341p.

J ACKSON, C.M. Soil chemical analyses. Englewood Cliffs, Prentice-Hall, 1965. p.195-196.

LINDNER, R.C. Rapid analytical methods for some of the more common inorganic constituints of plant tissues. Plant Physiol., 19:76-89, 1944.

RODRIGUES, J .R.M.; ANDRADE, M.J .B. \& CARVALHO, J .G. Resposta de cultivares de feijão (Phaseolus vulgaris L.) a doses de molibdênio aplicadas via foliar. In: REUNIÃO NACIONAL DE PESQUISA DE FEIJ ÃO, 5., Goiânia, 1996. Anais. Goiânia, EMBRAPA-CNPAF, 1996. p.76-78.
SIQUEIRA, J.O. \& FRANCO, A.A. Biotecnologia do solo. Fundamentos e perspectivas. Brasília, Ministério da Educação, 1988. p.179-216.

VIEIRA, C. Cultura do feijão. Viçosa, Universidade Federal de Viçosa, 1978. 146p.

VIEIRA, C.; NOGUEIRA, A.O. \& ARAÚJ O, G.A.A. Adubação nitrogenada e molíbdica na cultura do feijão. R. Agric., 67:117-124, 1992.

VIEIRA, R.F. Aplicação foliar de molibdênio e seu efeito nas atividades da nitrogenase e redutase do nitrato no feijoeiro em campo. Piracicaba, Escola Superior de Agricultura "Luiz de Queiroz", 1994. 188 p. (Tese de Doutorado) 